2 Newhouse, M L, Annals of Occupational Hygiene, 1973, 16, 97.

3 International Agency for Research on Cancer: Advisory Committee on Asbestos Cancers. Biological effects of asbestos. Annals of Occupational Hygiene, 1973, 16, 9.

${ }^{4}$ McEwen, J, et al, British Medical fournal, 1970, 4, 575.

Greenberg, M, and Davies, T A L, British fournal of Industrial Medicine, 1974, 31, 91.

${ }^{6}$ Gilson, J C, Proceedings of the Royal Society of Medicine, 1973, 66, 395.

\section{Communicating better}

Patients often say that doctors and nurses tell them too little, yet if they ask for information they are bewildered by unintelligible jargon. This confusion is disclosed when doctors check whether a patient is taking a prescribed drug. Between a quarter and two-thirds of patients may be taking the wrong dose and many omit part or all of a drug regimen-a common problem in tuberculosis. ${ }^{1}$ The need for better communication between doctors and the public was one item of Dr Charles Fletcher's provocative Rock Carling lecture ${ }^{2}$ four years ago. Medical schools and postgraduate institutions ought to pay more attention to communication, he argued, a possible solution being to set up a special association for studying it. Prompted by Fletcher's suggestion, the Nuffield Provincial Hospitals Trust looked into what research was going on, and, though the resulting book ${ }^{3}$ concentrates almost entirely on communication with patients, its contributors include social and clinical psychologists and a professor in communications research as well as two doctors.

Two of the Nuffield studies showed that nurses tend to overestimate psychological problems and underestimate physical ones, and that even final year students have a gross lack of interviewing skills. Such findings are grist to the antidoctor mill, and, in reviewing the book, the Guardian ${ }^{4}$ - which rarely loses an opportunity for doctor-bashing these days-has already commented that "medicine seems curiously inept in its communications with its customers." Yet we know little about how effectively other professional groups communicate with the public: how well do barristers get their message across to a jury, dons to their students, or even newspapers to their readers? In medicine the difficulties are compounded by a shortage of time for doctors and nurses and the fact that patients under stress tend to forget what they are told. Even special efforts to provide full information may not increase the proportion of patients who feel satisfied with communications. ${ }^{5}$ And when the public do believe a message they do not necessarily act on it-otherwise few people would continue to smoke cigarettes.

That said, however, improving communication in medicine is something we all need to think about. Students need to be taught much more about this aspect, even given their full curriculum. After the introductory clinical course emphasis on taking a good history and explanation to the patient has largely been lacking: Fletcher ${ }^{1}$ commented that communication was not mentioned at all by the Royal Commission on Medical Education ${ }^{6}$ and in only one undergraduate textbook of medicine. The Nuffield book contains several articles which will help teachers and students. The importance of communication other than speech (such as pauses, gestures, and eye contact) is emphasised in theory by Colin Fraser, and in practice by Maguire and Rutter, who found that some students had mannerisms which seriously hampered their interviews with patients. (One student conducted an interview while sprawled in a chair; the patient interpreted this as indifference and gave little information.) Students should be taught to use explicit guidelines for obtaining a case history, rather than imitating their teachers, who, like all experienced professionals, often take short cuts and intuitively follow promising leads. Rutter and Maguire describe such a set of guidelines, which develop interviewing skills, are geared to the time available for interview, and allow for a wide range and complexity of clinical problems. Philip Ley shows that patients will understand instructions and follow treatment better if close attention is paid to designing an instruction leaflet. This should be written in very easy English with the information presented as groups of facts and repeated. Most important, perhaps, students should be taught to listen-interrogation has its place, but time spent letting the patient talk relevantly is rarely wasted.

With the publication of the Nuffield book the time has come to draw together the strands of progress that has been made in improving communication and identify what needs to be done. For undoubtedly progress there has been. The work of Cicely Saunders, Hinton, and Cramond has revolutionised our understanding of the psychological needs of the dying. The British Breast Group now has a project for training surgeons to be more sensitive to the psychological needs of women with breast cancer. This and other surveys should be made easier by the recent information of various patient organisations who can let doctors know how and where they have failed to communicate. The stress of the interview for outpatients has been diminished by getting them to fill in a questionnaire about symptoms beforehand, ${ }^{7}$ a task which can also be done using a computer, ${ }^{8}$ or asking them to list the questions they want the doctors to answer. ${ }^{9}$ Even medical teaching has been studied, and we now know the elements that make a good lecture. ${ }^{10}$ Perhaps most encouragingly there are now in existence lively student groups, such as the London and Edinburgh Medical Groups, which are particularly concerned with the aspects of medicine that medical teachers have tended to forget. It is the students who must be convinced that communication is important. The behavioural sciences course recently introduced into the curriculum provides the chance to give it the right emphasis-and that chance should be grasped.

\footnotetext{
${ }^{1}$ Stewart, R B, and Cluff, L E, Clinical Pharmacology and Therapeutics, $1972,13,463$.

${ }^{2}$ Fletcher, C M, Communications in Medicine. London, Nuffield Provincial Hospitals Trust, 1973.

${ }^{3}$ Communication Between Doctors and Patients, ed A E Bennett. London, Nuffield Provincial Hospitals Trust, 1976, price $£ 3$.

4 Hebert, H, The Guardian, 20 May, p 13.

5 Hugh-Jones, P, Tanser, A R, and Whitby, C, British Medical fournal, $1964,2,660$.

6 Royal Commission on Medical Education, Report, Cmnd 3569. London, HMSO, 1968.

7 Hall, G H, British Medical fournal, 1972, 1, 42.

${ }^{8}$ Gledhill, V X, and Mathews, J D, British fournal of Hospital Medicine, 6, Suppl p 16.

${ }^{9}$ Hawkins, C F, Speaking and Writing in Medicine. Springfield, Thomas,

10 Cantrell, E G, British fournal of Medical Education, 1971, 5, 309.
} 